\title{
Layers of Nanocrystalline SiC as a New Type of Solid-State Hydrogen Storage
}

\author{
A. Guglya ${ }^{D},{ }^{1}$ A. Kalchenko, ${ }^{1}$ E. Lyubchenko $\left(\mathbb{D},{ }^{2}\right.$ Yu. Marchenko, ${ }^{1}$ and A. Semenov ${ }^{2}$ \\ ${ }^{1}$ National Science Center, Kharkov Institute of Physics and Technology, 1, Akademicheskaya Str., Kharkov 61108, Ukraine \\ ${ }^{2}$ National Technical University, Kharkov Polytechnic Institute, 2, Kyrpychova Str., Kharkov 61002, Ukraine \\ Correspondence should be addressed to E. Lyubchenko; e_lyubchenko@ukr.net
}

Received 20 May 2018; Revised 29 October 2018; Accepted 6 November 2018; Published 4 December 2018

Academic Editor: Carlos R. Cabrera

Copyright (c) 2018 A. Guglya et al. This is an open access article distributed under the Creative Commons Attribution License, which permits unrestricted use, distribution, and reproduction in any medium, provided the original work is properly cited.

This paper presents the results related to the investigation of layers of nanocrystalline silicon carbide (nc-SiC) obtained by direct ion deposition for the purpose of hydrogen accumulation. The parameters of the production process providing the largest amount of accumulated hydrogen (more than $5.5 \mathrm{wt} . \%$ ) were determined based on the mass spectrometric data on the desorption of atomic and molecular hydrogen from $\mathrm{nc}-\mathrm{SiC}$ films. Electron microscopic examination revealed the structural features that are responsible for absorption, retention, and desorption of hydrogen at relatively low temperatures and pressures. The study results suggest that the main structural elements acting as the hydrogen traps are the vacant positions of carbon in nc-SiC. The presence of a developed system of intercrystalline boundaries in investigated films promotes the hydrogen desorption at relatively low temperatures.

\section{Introduction}

Over the past decades, an ever-increasing demand for sources of energy alternative to charcoal, oil, and gas has been observing. One of the most accessible and energetically favorable sources can be hydrogen. But the main challenge hampering progress in the field of development and usage of electrical installations running on hydrogen fuel is the lack of solid materials that can accumulate the hydrogen in large amounts (>5.4 wt.\%) and release it at relatively low $(<400 \mathrm{~K})$ temperatures [1].

The large amounts of hydrogen adsorbed in the solid-state accumulators can be retained either by means of formation of chemical compounds or by physical adsorption of molecular hydrogen in micropores. In the first case, the hydrogen is absorbed in light metal hydrides $\left(\mathrm{MgH}_{2}, \mathrm{TiH}_{2}\right.$, and $\left.\mathrm{LiH}\right)$, in complex hydrides $\left(\mathrm{LiBH}_{4}, \mathrm{NaAlH}_{4}, \mathrm{KBH}_{4}, \mathrm{Li}-\mathrm{N}-\mathrm{H}, \mathrm{Mg}-\mathrm{N}-\mathrm{H}\right.$, and $\mathrm{Ca}-\mathrm{N}-\mathrm{H})$, or in intermetallic compounds $\left(\mathrm{Mg}_{2} \mathrm{Ni}, \mathrm{ZrV}_{2}\right.$, and $\mathrm{LaNi}_{5}$ ). In the second case, the developed porous structure of the samples is necessary for the absorption of molecular hydrogen. At the same time, the hydrogen can be accumulated both by the "thick-film" and "thin-film" samples (see, for example, [2]). Despite that the achievement of acceptable results for the accumulated hydrogen amount ( $\sim 9-10$ wt.\%) is possible in many cases, the high heat of hydrogen chemisorption $(>50 \mathrm{~kJ} / \mathrm{mole})$ prevents its release from the lattice at the temperatures below $573 \mathrm{~K}[3,4]$.

Currently, the metal-organic frameworks (MOFs), which consist of metal or metal-ion vertices connected by organic molecules known as organic linkers, are tested for physisorption of molecular hydrogen [5]. In addition, the carbon formations, such as nanotubes, nanofibers, fullerenes, graphenes, and composite nanoporous metalloid structures obtained using different vacuum deposition techniques, have been also studied [6]. Frame structures demonstrate a good level of the hydrogen adsorption (4-10 wt.\%); however, due to the low heat of physisorption (4-8 kJ/ mole), the hydrogen is released from them at the very low temperature $(<77 \mathrm{~K})$. Furthermore, certain hydrogen-based nanoporous structures can store the hydrogen at a temperature of up to $303 \mathrm{~K}$ but they cannot adsorb more than 2 wt. $\%$ of $\mathrm{H}_{2}$ [7].

As we have shown earlier, the nanocrystalline porous $(\mathrm{V}, \mathrm{Ti}) \mathrm{N}_{\mathrm{x}}$ thin films can absorb hydrogen in large amounts 
(>7 wt.\%) both in pores and inside nanograins [3, 4]. Such structures were obtained using the ion beam-assisted deposition (IBAD) (Figure 1; [5]). Formation of a nanoporous structure in the IBAD process occurs due to the bombardment of the depositing metal vapor with high-energy $(30 \mathrm{keV})$ ions of nitrogen [8-10].

In this investigation, we studied the possibility of using the nanocrystalline silicon carbide (nc-SiC) layers for adsorption and desorption of hydrogen. Unlike the nanocrystalline porous $(\mathrm{V}, \mathrm{Ti}) \mathrm{N}_{x}$ films, silicon carbide films were deposited at the bombardment with their own low-energy $(90 \mathrm{eV})$ ions. The thus produced nanocrystalline material has low density and good resistance to thermal, radiation, chemical, and mechanical influences. Therefore, this study aims to investigate the nanocrystalline $\mathrm{SiC}$ layers as the material for the accumulation and retention of hydrogen in large quantities.

\section{Materials and Methods}

The nc-SiC layers were formed on the single-crystal Si substrates using the original method of direct ion deposition [11]. A special feature of this method is that nanocrystals of various polytypes are formed in the growing $\mathrm{SiC}$ film depending on the temperature under the low-energy ion bombardment [12]. To study the kinetics of hydrogen adsorption and desorption in such structures, three sets of the nc-SiC films containing mixtures of cubic and rhombohedral phases $(3 C+21 R$ polytypic) were deposited on the single-crystalline $\mathrm{Cu}$ substrates. The films of equal thickness $(\sim 90 \mathrm{~nm})$ were deposited at the substrate temperatures of 940,970 , and $1000^{\circ} \mathrm{C}$ and labeled as $\mathrm{A}, \mathrm{B}$, and C films, respectively. These substrate temperatures were chosen based on previous detailed studies of the dependence of the nc-SiC film structure on the deposition temperature [12]. It was revealed that the silicon carbide at the given temperatures is a mixed crystalline/amorphous structure, where the crystalline SiC phase makes up 73,77 , and $80 \%$ in $\mathrm{A}, \mathrm{B}$, and $\mathrm{C}$ films, respectively. The relative content of the rhombohedral phase is increasing from A- to C-type films. Figure 2 presents the transmission electron microscope (TEM) images and selected area electron diffraction (SAED) patterns of A and C films.

The films were saturated with hydrogen at room temperature and at the pressure of $0.7 \mathrm{MPa}$ for 1 hour. In order to determine the absorbed hydrogen amount, the film in the vacuum chamber that was evacuated to a pressure of $10^{-3} \mathrm{~mm} \cdot \mathrm{Hg}$ and cut off from the pumping means was annealed in the temperature range up to $500^{\circ} \mathrm{C}$. The change in chamber pressure has been registered according to the thermometric lamp indications. The thermometric lamp records the change in the chamber pressure related to the hydrogen desorption as well as the desorption of all solubles and inert gases both from the film and the substrate. To measure the amount of "nonhydrogen" molecules in nc-SiC films, the samples were annealed in the unsaturated state. The amount of absorbed hydrogen was determined from the difference in chamber pressure after annealing of the saturated and unsaturated films.

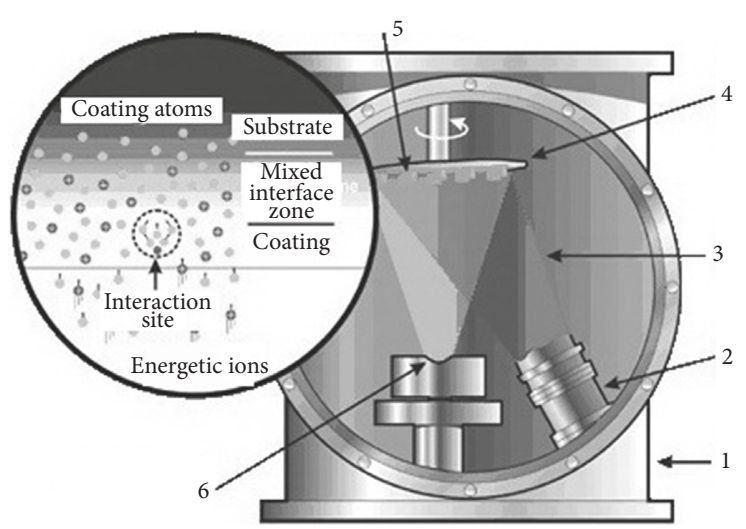

FIGURE 1: IBAD process: vacuum chamber (1), ions source (2), energetic ions (3), rotating substrate holder and monitor (4), components (5), and electron beam evaporator (6).

Determination of the temperature range of hydrogen desorption from nc-SiC films was carried out using mass spectrometric analysis of the samples in the same temperature range (up to $500^{\circ} \mathrm{C}$ ).

The structure and morphology of the film surface after 3 absorption/desorption cycles and their composition were investigated by transmission JEM-100CX and scanning JSM 7001F electron microscopes (TEM and SEM analyses).

\section{Results and Discussion}

The differential curves of the molecular and atomic hydrogen desorption from the $\mathrm{nc}-\mathrm{SiC}$ films versus temperature for the A, B, and C films are shown in Figure 3. The integral curve of hydrogen desorption from the films of all types based on the curves (Figures $3(a)-3(c)$ ) is shown in Figure 3(d).

The curves (Figures 3(a)-3(c)) differ in the position and in the number of desorption peaks of both atomic and molecular hydrogen. The complexity of the temperature dependence of the atomic and molecular hydrogen desorption from the films indicates both the mutual transformations of hydrogen atoms and molecules and the presence of various hydrogen traps differing in the capture efficiency.

The kinetic curves show that both dissociative chemisorption and physisorption, which are responsible for the atomic and molecular hydrogen accumulation, take place during the hydrogen adsorption. These processes are interrelated and represent the successive stages of gas absorption by the nc-SiC layer. The relationship between processes depends on a number of factors, including the gas pressure during processing, surface temperature, and structure and surface morphology.

In this paper, the special attention has been paid to the consideration of integral characteristics of the hydrogen accumulation and release from the films, because of their paramount importance for the practical use of the material for hydrogen storage. The results of detailed study of the adsorption and desorption of atomic and molecular hydrogen in $\mathrm{nc}-\mathrm{SiC}$ layers will be presented in our next paper. 


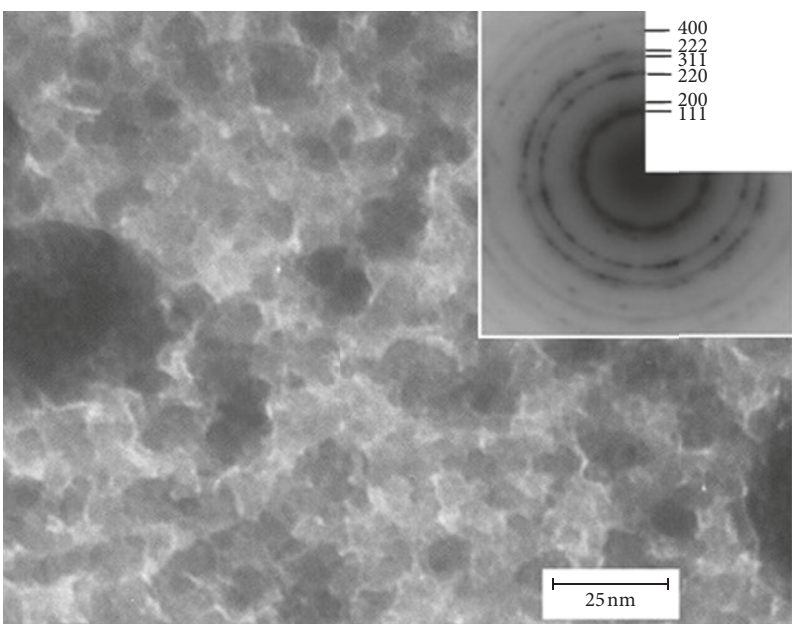

(a)

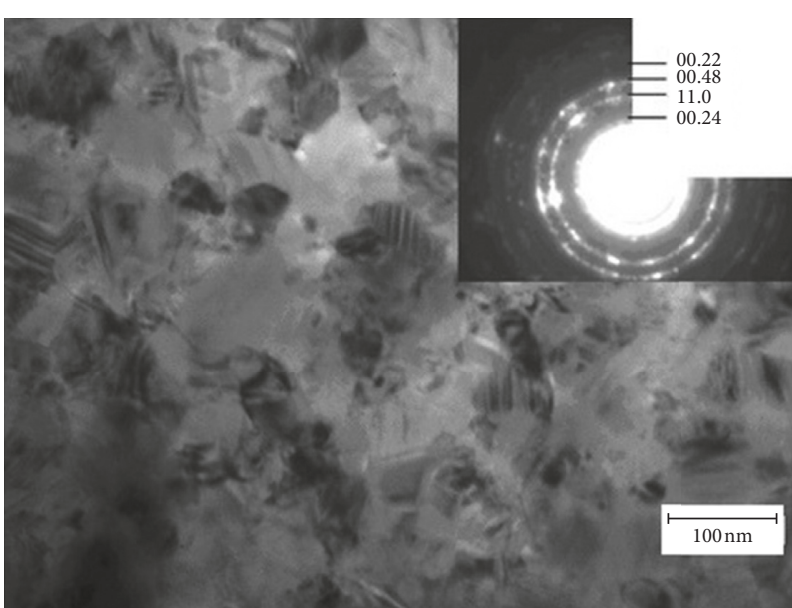

(b)

Figure 2: TEM images and SAED patterns of A (a) and C (b) films.

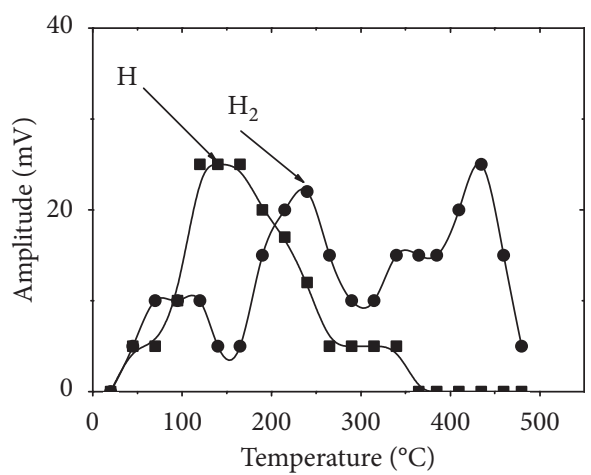

(a)

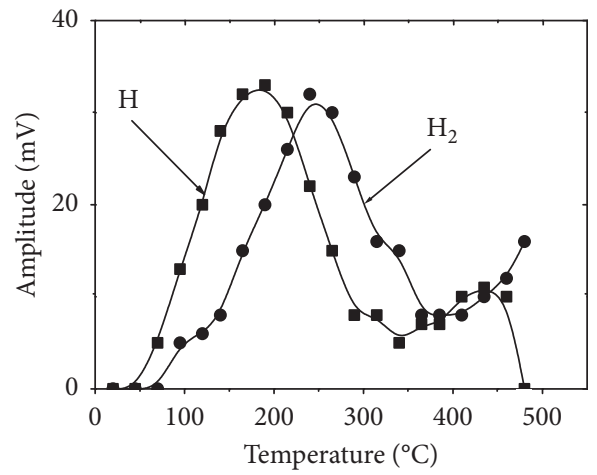

(c)

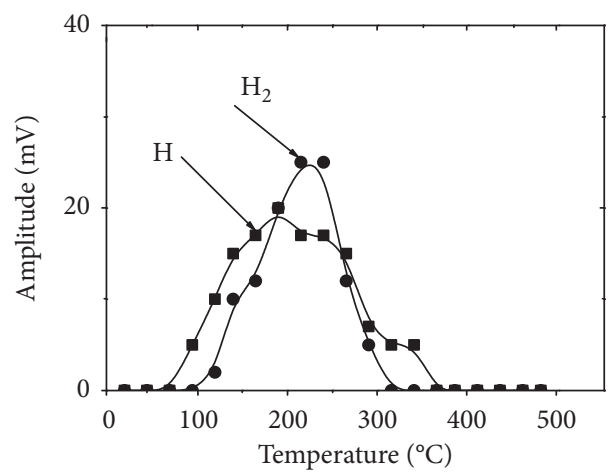

(b)

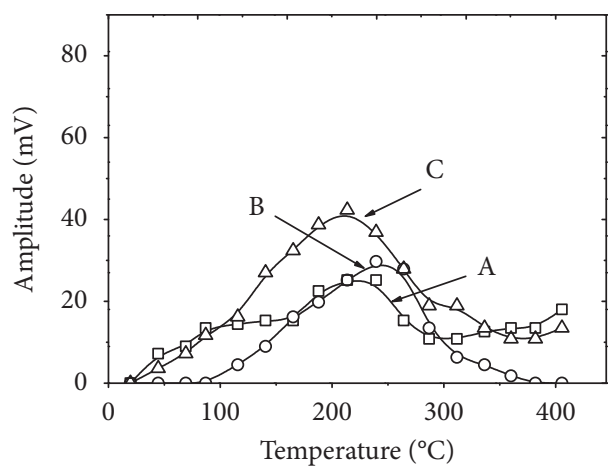

(d)

Figure 3: Mass spectrometric data on temperature dependences of atomic and molecular hydrogen desorption from the nc-SiC films of the A (a), B (b), and C (c) types and integral hydrogen desorption from nc-SiC A, B, and C films versus temperature (d).

The kinetic dependences of the integral hydrogen desorption from the films (Figure 3(d)) show that the maximum intensities of hydrogen desorption from all samples are located in close proximity to the range of $220-230^{\circ} \mathrm{C}$. This indicates that the main hydrogen amount in all investigated films was accumulated in the traps of the same type. It is expected that a small desorption maximum for A film at $\sim 100^{\circ} \mathrm{C}$ may be related to additional desorption channel of atomic hydrogen in comparison with other films.

In A and C films, in contrast to B film, a small amount of hydrogen is desorbed in the temperature range of 300$400^{\circ} \mathrm{C}$. As seen in Table 1 (column 5), the volumes of desorbed hydrogen in all samples in the temperature range from 20 to $400^{\circ} \mathrm{C}$ differ slightly. 
TABLE 1: Characteristics of the investigated film types.

\begin{tabular}{lcccc}
\hline Film type & $\begin{array}{c}\text { Integrative ratio Si/C } \\
(\mathrm{at} / \mathrm{at})\end{array}$ & $\begin{array}{c}\text { Average nanocrystal size } \\
(\mathrm{nm})\end{array}$ & $\begin{array}{c}\text { Desorbed hydrogen amount } \\
\left(\mathrm{H}_{2} / \mathrm{cm}^{3}\right)\end{array}$ & $\begin{array}{c}\text { Absorption capacity, calculated } \\
\text { for dense } \\
\left(3.21 \mathrm{~g} / \mathrm{cm}^{3}\right) \mathrm{SiC} \mathrm{film,}(\mathrm{wt} . \%)\end{array}$ \\
\hline 1 & 2 & 3 & 4 & 5 \\
$\mathrm{~A}$ & 1.24 & $60-80$ & $5.0 \times 10^{22}$ & 4.98 \\
$\mathrm{~B}$ & 1.30 & $50-70$ & $4.4 \times 10^{22}$ & 4.38 \\
C & 1.56 & $20-40$ & $5.5 \times 10^{22}$ & 5.48 \\
Single-crystalline SiC & 1.03 & & & \\
\hline
\end{tabular}

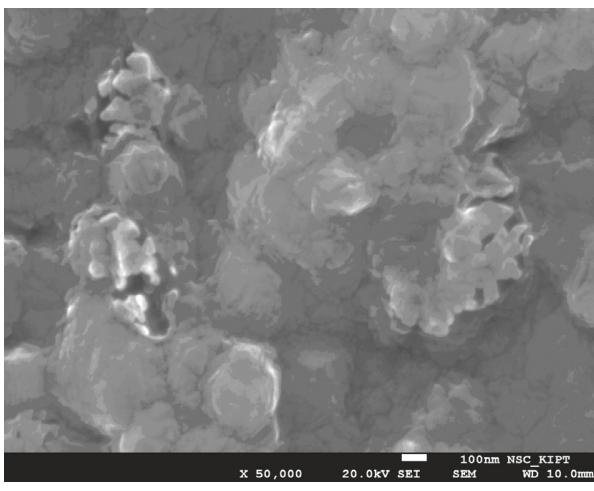

(a)

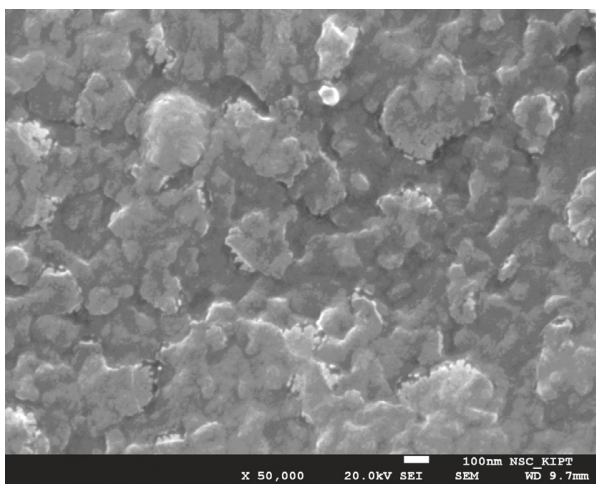

(c)

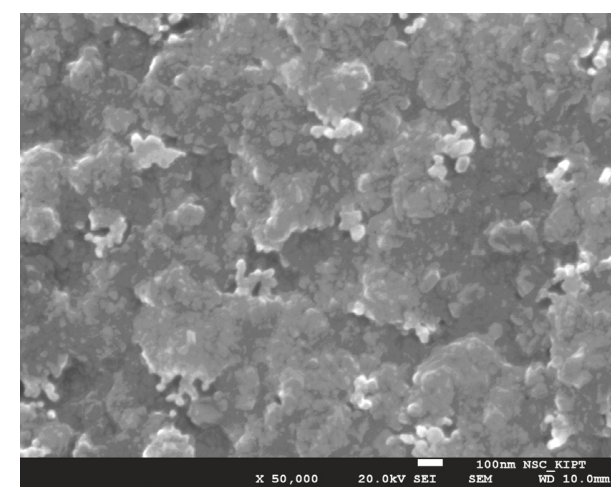

(b)

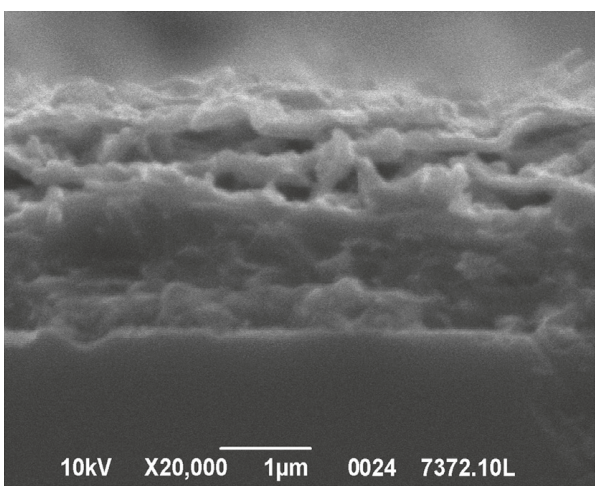

(d)

Figure 4: SEM images of the surfaces of nc-SiC films of A (a), B (b), and C (c) types and the cross section of nc-SiC film of C-type (d).

To explain the kinetic dependences and determine the mechanism of adsorption and desorption of accumulated hydrogen in nc-SiC films, a detailed electron microscopic study of the structure of the samples was carried out.

Analysis of SEM images (Figure 4) of the nc-SiC film surfaces revealed similar structural elements that are observed in all film types. The films consist of relatively large particles $(200-300 \mathrm{~nm})$ comprised nanocrystals of 20 $80 \mathrm{~nm}$ in size (Table 1). Surface pores are located between the macroparticles and nanocrystals. It can be seen that the surface concentration of large $(\sim 1 \mu \mathrm{m})$ pores between macroparticles decreases from A sample to $C$ sample while the concentration of smaller $(\sim 10 \mathrm{~nm})$ pores between nanocrystals increases. This pore distribution is also observed in the film volume. A cross section of $\mathrm{C}$ film (Figure 4(d)) demonstrates a typical pore distribution pattern. The pore sizes have been determined by the conditions of the film production and vary widely from $100 \mathrm{~nm}$ to $2 \mu \mathrm{m}$.

Compositional analysis of the films showed that the Si/C ratio increases sequentially from $\mathrm{A}$ film to $\mathrm{C}$ film due to the decrease of the relative carbon content. The observed dependence correlates with a decrease in the average size of nanocrystals (Table 1, column 3 ). Thus, a qualitative analysis of $\mathrm{SiC}$ film structure suggests that the investigated samples can absorb large amount of hydrogen in several types of traps: in interparticle pores, intercrystalline boundaries, and inside the nanocrystals. Since the intercrystalline pores in all films are very large, it is unlikely that these pores can retain a significant hydrogen amount at room temperature and atmospheric pressure.

It was thus suggested that most of hydrogen is absorbed by intercrystalline boundaries and nanocrystals. The surface area of nanocrystals is enriched by carbon vacancies. It 
TABLE 2: Amount of absorbed hydrogen in nitrogen- and boroncontaining complex hydrides.

\begin{tabular}{lcc}
\hline $\begin{array}{l}\text { Complex } \\
\text { hydride }\end{array}$ & $\begin{array}{c}\text { Amount of absorbed hydrogen } \\
\text { (wt.\%) }\end{array}$ & Reference \\
\hline $\mathrm{LiNH}_{2}$ & 5.5 & {$[15]$} \\
$\mathrm{LiNH}_{2}-\mathrm{MgH}_{2}$ & 4.5 & {$[16]$} \\
$\mathrm{LiBH}_{4}$ & 13.8 & {$[17]$} \\
$\mathrm{Mg}\left(\mathrm{BH}_{4}\right)_{2}$ & 14.9 & {$[18]$} \\
\hline
\end{tabular}

is known that equilibrium vacancy concentration in the surficial regions of nanocrystals is substantially higher than inside them. And, as the nanocrystal size decreases, an area with a high equilibrium vacancy concentration occupies an increasing share in the volume. It was shown $[13,14]$ that vacant positions of carbon in nanocrystalline $\mathrm{TiC}_{\mathrm{x}}$ can hold up to 4 hydrogen atoms. The $\mathrm{C}$ film contains the largest fraction of the crystalline phase. It consists of the smallest nanocrystals and, therefore, has the highest vacancy supersaturation (the greatest $\mathrm{Si} / \mathrm{C}$ ratio). It is the presence of a developed system of intercrystalline boundaries together with a high vacancy supersaturation in nanocrystals that ensure the absorption of large amount of hydrogen. The bulk nanoporosity provided the conditions for hydrogen absorption at room temperature and low hydrogen pressure and hydrogen desorption at relatively low temperatures.

Table 2 shows the results of the study of hydrogen absorption capacity of some nitrogen- and boron-containing complex hydrides [15-18]. It can be seen that the amount of absorbed hydrogen (in weight percents) exceeds the results obtained for nc-SiC (Table 1, column 5). Nevertheless, we believe that the weight content of hydrogen in $\mathrm{SiC}$ films is high enough and meets the requirements of the U.S. Department of Energy for hydrogen storage materials [1]. The calculations are based on the assumption that the density of the material under investigation was $3.21 \mathrm{~g} / \mathrm{cm}^{3}$, and it did not contain pores. In fact, as shown above (Figure 4(d)), the examined films contain a lot of pores and, as a result, the film density should be much lower, and the hydrogen content is higher than the calculated values. In addition, the density of silicon is significantly higher than the density of lithium and magnesium. Therefore, if we calculate the bulk density of absorbed hydrogen (Table 1, column 4) even without taking into account the presence of pores, it can be stated that nc$\mathrm{SiC}$ exhibits high-absorption properties.

\section{Conclusions}

Research suggests that the layers of nanocrystalline $\mathrm{SiC}$ are a promising material for the hydrogen accumulation. It was found that the main traps for absorbing hydrogen in them are the intercrystalline boundaries and the vacant positions of carbon in nc-SiC. The maximum hydrogen content in the film of C-type obtained at a higher substrate temperature $\left(1000^{\circ} \mathrm{C}\right)$ as compared to $\mathrm{A}$ - and B-type films can be associated with a higher concentration of the nanocrystalline phase and a higher equilibrium concentration of vacancies in them. In addition, a well-developed system of intercrystalline boundaries and nanopores in $\mathrm{nc}-\mathrm{SiC}$ films provides desorption of hydrogen at relatively low temperatures.

This research did not receive any specific grant from funding agencies in the public, commercial, or not-for-profit sectors.

\section{Data Availability}

The data used to support the findings of this study are available from the corresponding author upon request.

\section{Additional Points}

Highlights. (i) The layers of nanocrystalline SiC are promising for hydrogen accumulation. (ii) The intercrystalline boundaries and vacant positions of carbon are the main traps for hydrogen absorption in nc-SiC. (iii) The largest hydrogen quantity is absorbed in the films with the greater content of nanocrystalline phase and high-vacancy concentration. (iv) The well-developed system of intercrystalline boundaries and nanopores provides the hydrogen desorption at relatively low temperatures.

\section{Conflicts of Interest}

The authors declare that they have no conflicts of interest.

\section{References}

[1] U.S. Department of Energy, "Energy efficiency and renewable energy," Hydrogen Storage, https://www.energy.gov/eere/ fuelcells/hydrogen-storage.

[2] I. P. Jain, Y. K. Vijay, L. K. Malhotra, and K. S. Upadhyay, "Hydrogen storage in thin film metal hydrides-a review," International Journal of Hydrogen Energy, vol. 13, no. 1, pp. 15-23, 1988.

[3] I. P. Jain, P. Jain, and A. Jain, "Novel hydrogen storage materials: a review of lightweight complex hydrides," Journal of Alloys and Compounds, vol. 503, no. 2, pp. 303-339, 2010.

[4] I. P. Jain, "Hydrogen the fuel for 21st century," International Journal of Hydrogen Energy, vol. 34, no. 17, pp. 7368-7378, 2009.

[5] D. J. Collins and H. C. Zhou, "Hydrogen storage in metalorganic frameworks," Journal of Materials Chemistry, vol. 17, no. 30, pp. 3154-3160, 2007.

[6] R. Ströbel, J. Garche, P. T. Moseley, L. Jörissen, and G. Wolf, "Hydrogen storage by carbon materials," Journal of Power Sources, vol. 159, no. 2, pp. 781-801, 2006.

[7] A. Züttel, P. Sudan, P. Mauron, T. Kiyobayashi, C. Emmenegger, and L. Schlapbach, "Hydrogen storage in carbon nanostructures," International Journal of Hydrogen Energy, vol. 27, pp. 203-212, 2002.

[8] A. Guglya, E. Lyubchenko, M. Yu, E. Solopikhina, and V. Vlasov, "Crystal lattice of solid body can store simultaneously both molecules and atoms of hydrogen in quantities," International Journal of Hydrogen Energy, vol. 41, no. 22, pp. 9410-9417, 2016.

[9] A. Goncharov, A. Guglya, A. Kalchenko, E. Solopikhina, V. Vlasov, and E. Lyubchenko, "Nanocrystalline porous hydrogen storages based on vanadium and titanium nitrides," 
Journal of Nanotechnology, vol. 2017, Article ID 4106067, 10 pages, 2017.

[10] A. Guglya and I. Marchenko, in Deposition and Mechanisms: Ion Beam-Assisted Deposition Comprehensive guide for nanocoatings technology, Vol. 1, pp. 45-69, NOVA Press, New York, NY, USA, 2015.

[11] A. V. Semenov, V. M. Puzikov, M. V. Dobrotvorskaya, A. G. Fedorov, and A. V. Lopin, "Nanocrystalline SiC films prepared by direct deposition of carbon and silicon ions," Thin Solid Films, vol. 516, no. 10, pp. 2899-2903, 2008.

[12] A. V. Semenov, V. M. Puzikov, E. P. Golubova, V. N. Baumer, and M. V. Dobrotvorskaya, "Low-temperature production of silicon carbide films of different polytypes," Semiconductors, vol. 43, no. 5, pp. 685-689, 2009.

[13] A. Gringoz, N. Glandu, and S. Valette, "Electrochemical hydrogen storage in $\mathrm{TiC}_{0.6}$, not in $\mathrm{TiC}_{0.9}$," Electrochemistry Communications, vol. 11, no. 10, pp. 2044-2047, 2009.

[14] H. Ding, X. Fan, C. Li, X. Liu, D. Jiang, and C. Wang, "Firstprinciples study of hydrogen storage in non-stoichiometric $\mathrm{TiC}_{\mathrm{x}}$," Journal of Alloys and Compounds, vol. 551, pp. 67-71, 2013.

[15] T. Ichikawa, S. Isobe, N. Hanada, and H. Fujii, "Lithium nitride for reversible hydrogen storage," Journal of Alloys and Compounds, vol. 365, no. 1-2, pp. 271-276, 2004.

[16] W. Luo, "LiNH2-MgH2: a viable hydrogen storage system," Journal of Alloys and Compounds, vol. 381, no. 1-2, pp. 284287, 2004.

[17] H. W. Li, Y. Yan, S. Orimo, A. Züttel, and G. M. Jensen, "Recent progress in metal borohydrides for hydrogen storage," Energies, vol. 4, no. 1, pp. 185-214, 2011.

[18] G. Soloveichik, "Metal borohydrides as hydrogen storage materials," Material Matters, vol. 2, pp. 11-14, 2007. 


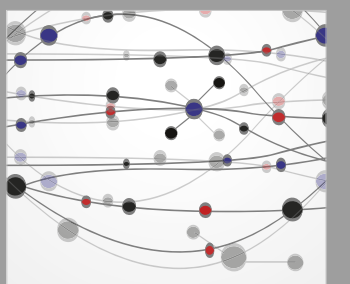

The Scientific World Journal
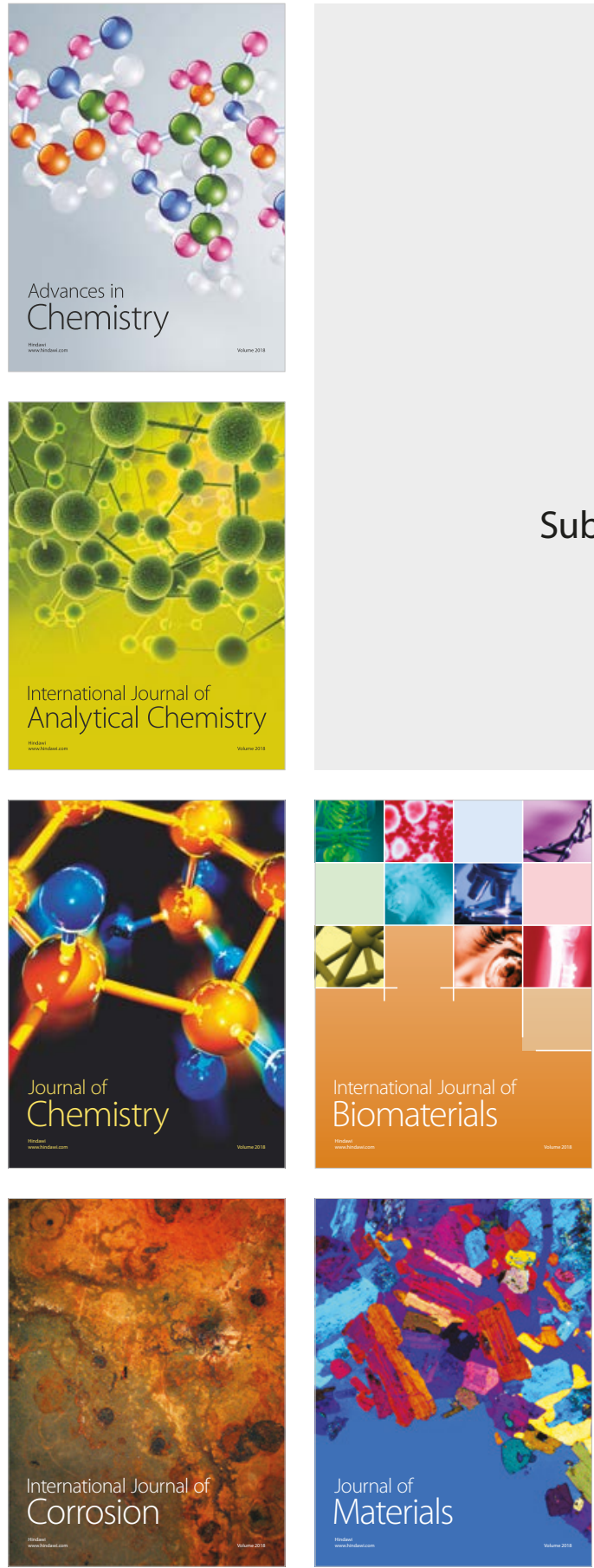

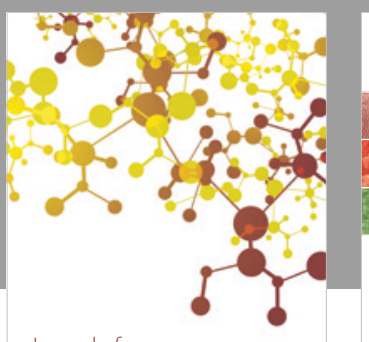

Journal of

Applied Chemistry
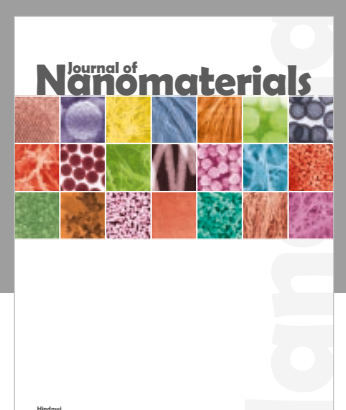

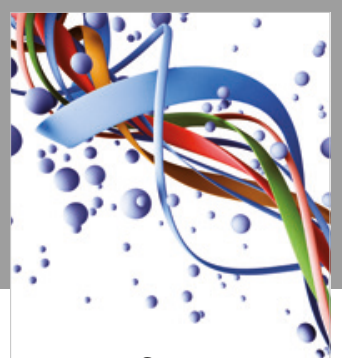

Scientifica

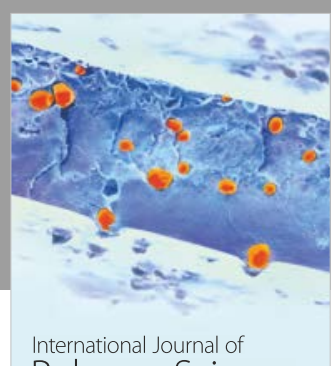

Polymer Science

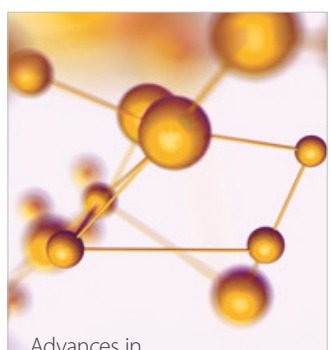

Physical Chemistry
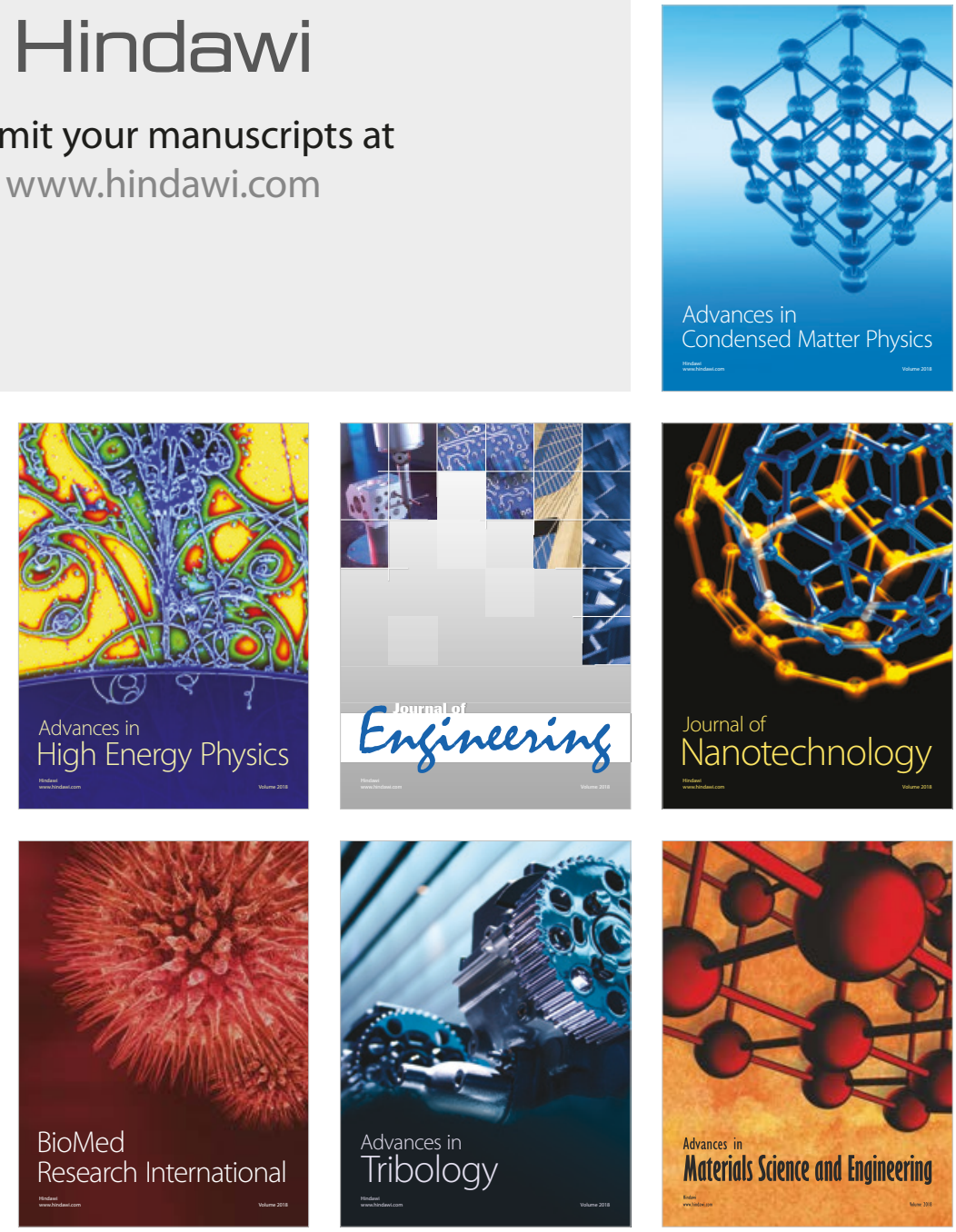